\title{
The Role of Leadership Spirituality in Increasing Employee Engagement with Leadership Communication as Moderator
}

\author{
Rahayu Sri Purnami ${ }^{1, *}$ Syamsul Hadi Senen ${ }^{2}$
}

\author{
${ }^{1}$ Universitas Pendidikan Indonesia \\ ${ }^{2}$ Universitas Pendidikan Indonesia \\ *Corresponding author.Email: rahayusripurnami@upi.edu
}

\begin{abstract}
Employee engagement is an important factor for employee's performance. However, employees dissatisfied with their supervisors were disengaged. This research is an exploratory study with the type of research is literature studies. Leadership is needed to increase engagement at work. Spiritual leadership is a concept of leadership with an emphasis on 2 things: creating a vision wherein the organization members experience a sense of calling in that their life has meaning and makes a difference; establishing a social / organizational culture based on altruistic love where leaders and followers have genuine care, concern, and appreciation for both self and others, producing a sense of membership and feel understood and appreciated. The effectiveness of spiritual leadership will increase with the support of leadership communication skills in delivering messages. Employee engagement as intrinsic motivation plays an important role in improving employee performance. Spiritual leadership can further enhance employee engagement if supported by good leadership communication.
\end{abstract}

Keywords: Employee Engagement, Leadership Spirituality, Leadership Communication.

\section{INTRODUCTION}

Employee performance will increase if supported by the presence of both intrinsic motivation and extrinsic motivation. It was shown that intrinsic motivation in the form of engagement at work plays a dominant role with the largest percentage of $34 \%$, while autonomy plays a role of $12 \%$, finance by $11 \%$, recognition by $21 \%$, and a culture of mutual respect, trust and intimacy by $22 \%$ [1]. The discussion on engagement atwork was initiated by an ethnographer named Kahn in 1990 who stated that engagement is the benefit of organizational members when carrying out their role at work [2]. Discussion about engagement at work develops into a concept called employee engagement. Engaged employees define as those who are mentally and emotionally invested in their work and contribute to employer's success. However, the workforce in the United States wass only one third of them engaged in their work. [3] While in Indonesia according to the results of Dale Carnegie Indonesia's research in 2014, only $29 \%$ of the workforce was engaged in their work, $52 \%$ included in partially engaged and 19\% disengaged. Employees who are dissatisfied with their immediate supervisor experience disengagement. Employees involved as much as $61 \%$ reported that they were treated with dignity in their positions and as many as 65\% reported open communication between employees and management.

Organizations need good leadership to be able to adapt to increasingly complex systems and to be able to continue to grow. Leadership for sustainability requires leaders who have extraordinary abilities such as ability to read and predict complexity, think through complex problems, engage groups in dynamic adaptive organizational change and have the emotional intelligence to actively engage their own emotions associated with complex problem solving. [4] Leaders who care about subordinates, listen and respond to their opinions, can be trusted and do what is said can increase employee engagement. [5] Organizational culture that is able to adapt requires a leader who has autonomy, initiative for progress, creative, risk-taker, able to learn from uncertain situations and have new 
goals and strategies that are in line with organizational growth. Key elements in modern leadership involve cooperation, consideration, agreement, fairness and social equality. [6] Spirituality in leadership related to the discovery of meaning becomes a fundamental need for both leaders and followers for spiritual survival so they become more organizationally committed and productive [7].

\section{METHODS}

The research method used was an exploratory method, which aims to deepen knowledge about a particular symptom, or get new ideas about certain symptoms, with the aim at formulating the problem in more detail. The data collection technique was literature study.

\section{RESULTS AND DISCUSSION}

\subsection{Employee Engagement}

Employee engagement is a level or a high level of an individual to invest himself in the work assigned to be completed. An engaged person will be involved, satisfied, committed, enthusiastic and have the motivation to find meaning in his work [8]. Whereas [9] stated that engaged employees will give what they have in their work and involve four conditions namely urgency, focus, intensity and enthusiasm. Engagement means psychologically involved in, connected with, and committed to the completion of work [10]. Employee engagement is engagement, satisfaction and enthusiasm of an individual to the work he was doing. Employees with high levels of engagement are very passionate about their work and feel very connected to their companies and conversely employees who do not engage tend to work when they are not enthusiastic and focused on their work [11].

Salanova and Schaufeli said that the dimensions of employee engagement consisted of: 1) Enthusiasm (vigor), a condition marked by high energy, the ability to rise again, perseverance, and the desire to give more effort. 2) Dedication is enthusiasm, sense of purpose, inspiration, and pride in the work. 3) Absorption is a state of concentration, preoccupation in carrying out the role at work and feeling happy with working conditions [2].

\subsection{Spiritual Leadership}

Spiritual leadership is a set of values, attitudes, and behaviors needed to motivate others intrinsically so that they have spiritual resilience through calling and membership. Vision, altruistic love, hope/belief shows the quality of leadership spirituality. The vision includes: great attention to key stakeholders, outlining the goals and journey to be taken, describing noble ideals, encouraging hope/ belief, setting standards of excellence.
Altruistic love includes forgiveness, kindness, integrity, empathy/affection, honesty, patience, courage, trust/loyalty, humility. Expectations/beliefs consists of endurance, perseverance, doing what is needed, expanding goals, hopes for appreciation and victory.

Spiritual leadership combines the four elements of human existence that are body, mind, heart, and spirit so that people are motivated for high performance, have increased organizational commitment, and personally experience joy, peace, and serenity. Spiritual leadership is very important for the transformation and sustainability of a learning organization [7]. Spiritual leadership is also related to environmental leadership, namely the ability to influence individuals and mobilize organizations to realize a vision of long term ecological sustainability [12]. Individual spiritual beliefs at top level leaders influence strategic decision making in strategic leadership such as when filtering and frame information [13]. Spiritual calling can increase job satisfaction and organizational commitment [14].

\subsection{Leadership Communication}

Factors that contribute to employee engagement consists of individual factors, environmental characteristics, and organizational factors. Individual factors consist of positive and optimistic personalities, proactive individuals, and awareness. While the environmental characteristics consist of the characteristics of work-employee will be more engaged when his work varies and get feedback from what he does, employee-leadership will be more engaged when the leader is charismatic and there is a relationship based on mutual trust between superiors and subordinates, stressor engagement will increase when stress triggers a little. Organizational factors include five factors, namely career development opportunities, performance management, organizational reputation, communication and recognition [9].

Leadership communication in the controlled, purposeful transfer of meaning by which leaders influence a single person, a group, an organization or a community. Leadership communication consists of three layers from the innermost i.e. the core, then the managerial, and the outer layer, the corporate. At the core layer, a leader must master three things, namely strategy, writing, and speaking. Furthermore, in leading groups, the managerial layer must master emotional intelligence, cultural literacy, listening, teams and meetings management, coaching, and mentoring. While in the corporate layer that is organizational leadership, a leader must master the skills of employee relations, change communication, media relations, crisis communication, image and reputation management [15]. Leaders who are able to listen well contribute to the mental health of employees. Non listening and self-centered leadership can worsen employee mental health [16]. Leadership 
communication both verbally and non-verbally plays an important role in strengthening organizational reputation and in times of crisis a leader must initiate and communicate with stakeholders [17].

The relationship between spiritual leadership and employee engagement with leadership communication as moderator is shown in figure 1 .



Figure 1. The Role of Spiritual Leadership in Employee Engagement with Leadership Communication as moderator.

\section{CONCLUSIONS}

Employee engagement as intrinsic motivation plays an important role in improving employee performance. Spiritual leadership can further enhance employee engagement if supported by good leadership communication.

\section{REFERENCES}

[1] R. Singh, "The Impact of Intrinsic and Extrinsic Motivators on Employee Engagement in Information Organizations," vol. 57, no. 2, pp. $197-$ 207, 2016.

[2] A. M. Saks, "Journal of Management, Spirituality \& Workplace spirituality and employee engagement," J. Manag. Relig., vol. 8:4, pp. 317-340, 2011.

[3] G. Dessler, Fundamentals of Human Resource Management, Third Edit. Essex: Pearson Education, 2014.
[4] L. Metcalf and S. Benn, "Leadership for Sustainability: An Evolution of Leadership Ability," no. March 2012, pp. 369-384, 2013.

[5] J. C. Hughes and E. Rog, "Talent management within hospitality organizations," 2008.

[6] Y. Meng, "Spiritual leadership at the workplace: Perspectives and theories (Review)," no. 5, pp. 408 412, 2016.

[7] L. W. Fry, "Toward a theory of spiritual leadership," vol. 14, no. September, pp. 693-727, 2003.

[8] A. J. Dubrin, Fundamentals of - Organizational Behavior, Sixth Edit. Academic Media Solutions, 2019.

[9] A. Kinicki and M. Fugate, Organizational Behavior. New York: Mc Graw Hill Edication, 2016.

[10] G. Dessler, Human Resource Management, Thirteenth. New Jersey: Pearson Education, 2013.

[11] S. P. Robbins and T. A. Judge, Essentials of Organizational Behavior, Fourteenth. Essex: Pearson Education, 2018.

[12] J. Crossman and J. Crossman, "Environmental and Spiritual Leadership : Tracing the Synergies from an Organizational Perspective,” pp. 553-565, 2011.

[13] K. A. Phipps, "Spirituality and Strategic Leadership: The Influence of Spiritual Beliefs on Strategic Decision Making,” pp. 177-189, 2012.

[14] M. J. Neubert and K. Halbesleben, "Called to Commitment: An Examination of Relationships Between Spiritual Calling, Job Satisfaction , and Organizational Commitment," J. Bus. Ethics, pp. 859-872, 2015.

[15] A. A. E. I and B. D. J. Barrett, "Leadership Communication: A Communication Approach for Senior-Level Managers," 1991.

[16] A. Nyberg, C. Leineweber, L. L. M. Hanson, G. Oxenstierna, and H. Westerlund, "Non-Listening and Self Centered Leadership - Relationships to Socioeconomic Conditions and Employee Mental Health," vol. 7, no. 9, pp. 1-10, 2012.

[17] J. Jamal and H. A. Bakar, "The Mediating Role of Charismatic Leadership Communication in a Crisis : A Malaysian Example," 2015. 